\title{
HELENA POTIGUARA: BIOGRAFIA DA EDUCADORA INDÍGENA (1954-2009)
}

\author{
HELENA POTIGUARA: BIOGRAFÍA DE LA EDUCADOR INDÍGENA (1954-2009) \\ HELENA POTIGUARA: BIOGRAPHY OF THE INDIGENOUS EDUCATOR (1954- \\ 2009)
}

\author{
Arliene Stephanie Menezes PEREIRA ${ }^{1}$ \\ Ana Carolina Braga de SOUSA ${ }^{2}$ \\ Lia Machado Fiuza FIALHO ${ }^{3}$
}

RESUMO: A pesquisa trata da biografia de Maria Helena Gomes, conhecida como Helena Potiguara, mulher educadora indígena de liderança reconhecida, na etnia Potiguara, por seu protagonismo educacional na cidade de Crateús-CE. Situado no campo da História da Educação, com aporte teórico na História Cultural, o estudo objetiva compreender a formação educativa e as práticas políticas, tecidas pela educadora Helena Potiguara, que lhe conferiram destaque na comunidade Potiguara (1954-2009). Por meio da metodologia da história oral de vida entrecruzada com fontes documentais, elabora-se uma narrativa biográfica hermenêutica com ênfase na trajetória formativa e política de Helena Potiguara. Os resultados demonstram que Helena Potiguara rompeu com o silenciamento de suas origens étnicas a partir dos trabalhos com as comunidades eclesiais de base da igreja católica, protagonizando uma educação indígena diferenciada, o que lhe permitiu liderar mobilizações coletivas nas representações identitárias sobre os indígenas na cidade de Crateús.

PALAVRAS-CHAVE: Educação indígena. Maria Helena Gomes. História da educação.

RESUMEN: La investigación trata de la biografía de María Helena Gomes, conocida como Helena Potiguara, educadora indígena de reconocido liderazgo, en la etnia Potiguara, por su rol educativo en la ciudad de Crateús-CE. Ubicado en el campo de la Historia de la Educación, con un aporte teórico a la Historia Cultural, el estudio tiene como objetivo comprender la formación educativo y las prácticas políticas, tejido por la educadora Helena Potiguara, que le dio protagonismo en la comunidad Potiguara (1954-2009). A través de la metodología de la historia oral entrelazada con fuentes documentales, se elabora una narración biográfica hermenéutica con énfasis en la trayectoria formativa y política de Helena Potiguara. Los resultados muestran que Helena Potiguara rompió el silencio de su origen étnico a través de su trabajo con las comunidades eclesiásticas de la Iglesia Católica, liderando una educación indígena diferenciada, que le permitió liderar movilizaciones colectivas en las representaciones identitarias sobre los pueblos indígenas de la ciudad de Crateús.

\footnotetext{
${ }^{1}$ Universidade Estadual do Ceará (UECE), Fortaleza - CE - Brasil. Doutoranda no Programa de Pós-Graduação em Educação. ORCID: https://orcid.org/0000-0002-3042-538X. E-mail: stephanie.menezes@ifce.edu.br ${ }^{2}$ Universidade Estadual do Ceará (UECE), Fortaleza - CE - Brasil. Doutoranda no Programa de Pós-Graduação em Educação. ORCID: https://orcid.org/0000-0001-6959-5493. E-mail: carolbraga30@yahoo.com.br

${ }^{3}$ Universidade Estadual do Ceará (UECE), Fortaleza - CE - Brasil. Professora Permanente do Programa de PósGraduação em Educação. Doutorado em Educação (UFC). Bolsista de Produtividade em Pesquisa do CNPq Nível 2. ORCID: https://orcid.org/0000-0001-8415-9921. E-mail: lia_fialho@yahoo.com.br
} 
PALABRAS CLAVE: Educación indígena. Maria Helena Gomes. Historia de la educación.

ABSTRACT: The research deals with the biography of Maria Helena Gomes, known as Helena Potiguara, an indigenous educator of recognized leadership, in the Potiguara ethnic group, for her educational role in the city of Crateus-CE. Located in the field of the History of Education, with a theoretical contribution to Cultural History, the study aims to understand the educational background and political practices woven by educator Helena Potiguara, which gave it in the Potiguara community (1954-2009). Through the methodology of oral life history intertwined with documentary sources, a hermeneutic biographical narrative with an emphasis on Helena Potiguara's formative and political trajectory is elaborated. The results show that Helena Potiguara broke the silence of her ethnic origins through her work with the ecclesial communities of the Catholic Church, leading a differentiated indigenous education, which allowed her to lead collective mobilizations in the identity representations of the indigenous people in the city of Crateus.

KEYWORDS: Indigenous education. Maria Helena Gomes. History of education.

\section{Introdução}

Há na minha província uma ribeira, / Um sertão, onde eu vi a vez primeira / Sorrir-me da existência a doce luz: / Tem o nome da tribo que o habitava, / Quando ao rude tapuia entregue estava, / Esse nome, sabei-o, - Cratheús. (Poesia "A Virgem do Crateús" de José Croroliano de Souza Lima, 1870, s/ $\left.\mathrm{p}^{4}\right)$

A epígrafe inicial deste texto destaca a cidade de "Cratheús", hoje denominada Crateús, situada no sertão cearense, distante $350 \mathrm{~km}$ da capital Fortaleza, conhecida como a Princesa do Oeste. Essa região é habitada por um representativo contingente de povos indígenas, que lá se instalaram desde antes da colonização brasileira. A palavra Crateús possui origem em um topônimo indígena provavelmente Tapuia composta da palavra kra (seco), té (coisa ou lugar) e us (povo); o que significa povo do lugar seco. E é nessa cidade sertaneja que moram os povos Potiguaras, para os quais o seu contexto educacional é evidenciado nesse estudo.

Para entender a história da educação indígena no estado do Ceará interessa considerar vários documentos que são percebidos como os marcos legais deste tipo de educação. Primeiramente cabe destacar a Constituição Federal de 1988 (BRASIL, 1988) que assegurou aos indígenas uma educação diferenciada, específica e bilíngue em seus artigos 231 e 232.

\footnotetext{
${ }^{4}$ Poesias Publicadas em 1870 (na mesma ordem da edição de 1870) (Notas de A. Tito Filho na Edição de 1973) e organizadas por Ivens Mourão (tetraneto do autor). Disponível em: https://www.portalentretextos.com.br/post/ obra-completa-de-jose-coriolano-de-sousa-lima. Acesso em: 01 de abr. de 2020.
} 
Também se assinala o Decreto $\mathrm{n}^{\circ} 26$ de 4 de fevereiro de 1991 (BRASIL, 1991), que trata especificamente da educação indígena:

\begin{abstract}
Art. $1^{\circ}$ Fica atribuída ao Ministério da Educação a competência para coordenar as ações referentes à educação indígena, em todos os níveis e modalidades de ensino, ouvida a FUNAI (Fundação Nacional do Índio). Art. $2^{\circ}$ As ações previstas no Art. $1^{\circ}$ serão desenvolvidas pelas secretarias de educação dos estados e municípios em consonância com as secretarias nacionais de educação do Ministério da Educação (BRASIL, 1991, s/p).
\end{abstract}

Outro aporte relevante é a Lei de Diretrizes e Bases da Educação Nacional (LDB), que designou, em seu Art. 78, o Sistema de Ensino da União com a colaboração das agências federais de fomento à cultura e de assistência aos índios, ao desenvolver programas integrados de ensino e pesquisa para ofertar uma educação escolar bilingue e intercultural aos povos indígenas (BRASIL, 1996). A Secretaria de Educação do Ceará (SEDUC) também constatou e reconheceu as escolas indígenas no estado do Ceará, por meio do Decreto $n^{\circ} 25.970$, de 31 de julho de 2000: "cria as escolas indígenas que indica e dá outras providências", e assegurou as "especificidades e peculiaridades de cada etnia" (CEARÁ, 2000, p. 2). O mesmo aconteceu posteriormente por meio de outros decretos estaduais, como os de $\mathrm{n}^{\circ} 30.165$ de 10 de maio de 2010 e n⿳0 30.765 de 05 de dezembro de 2011.

Porém, os textos desses documentos não permitem, isoladamente, uma compreensão pormenorizada das minucias que envolvem o contexto educacional dos grupos indígenas cearenses, em especial, dos Potiguaras. De tal modo, uma investigação de campo, que considera aspectos microssociais, lançando luz às subjetividades de uma mulher indígena educadora, torna factível refletir sobre algumas tensões, percalços e conquistas dos povos indígenas no que concerne à formação educacional feminina e às práticas políticas empreendidas para a educação de outras gerações. Especialmente, quando essa mulher possui uma história de vida permeada por desafios formativos, que se imbricam na vida de uma coletividade feminina, e larga trajetória de atuação na história da educação dessa comunidade como professora; como é o caso de Maria Helena Gomes, doravante apenas Helena Potiguara, como ficou conhecida.

Elaborou-se um problema central para o estudo: Como uma mulher indígena residente no município de Crateús, interior do Ceará, conseguiu escolarização para tornar-se professora indígena e galgar posição de liderança comunitária reconhecida por suas práticas educativas e políticas diferenciadas? Para redarguir essa problemática, desenvolveu-se um estudo científico com o objetivo de compreender a formação educativa e as práticas políticas, tecidas 
pela educadora Helena Potiguara, que lhe conferiram destaque na comunidade Potiguara (1954-2009).

Desenvolveu-se uma pesquisa do tipo biográfica (DOSSE, 2015), situada no campo da história da educação, amparada teoricamente na história cultural (BURKE, 1992) e metodologicamente na história oral de vida (ALBERTI, 2006), que possibilitou reconstituir o contexto educacional e elaborar uma narrativa biográfica de Helena Potiguara. Mulher cuja trajetória de vida esteve marcada pelas suas atuações educacionais, que the possibilitaram protagonizar uma formação indígena diferenciada não apenas entre as etnias que compõem a comunidade Potiguara, mas também no seu entorno, inter-relacionado indissociavelmente à história individual e coletiva.

O estudo biográfico de Helena Potiguara torna-se relevante por possibilitar não apenas preservar a memória e a história da educação de uma comunidade, mas também por talhar reconhecimento ao valor das histórias de vida dos povos indígenas, sob suas perspectivas formativas, ao trazer à tona as nuances específicas de um contexto educacional muitas vezes invisibilizado e relegado a segundo plano de importância na narrativa histórica. Helena Potiguara ao consagrar-se personagem de referência entre os indígenas do estado, em especial na região de Crateús, por sua capacidade de liderança, não somente contribuiu com o processo educativo dos que com ela conviveram, mas também no âmbito político por sua atuação nos movimentos de ocupações de terra (LIMA, 2010; PALITOT, 2008).

Para melhor compreensão leitora, o artigo subdivide-se em cinco seções, quais sejam: "Introdução", na qual se explicitou a temática da pesquisa (educação indígena), sua delimitação (Potiguaras de Crateús-CE), o problema e objetivo do estudo, bem como a sua relevância; "Percurso teórico-metodológico", onde se esclareceu o tipo do estudo, a técnica de coleta de dados, os aspectos éticos, dentre outros aspectos metodológicos; "Karatius: A quebra de silenciamento", em que evidenciou-se a trajetória política de Maria Helena Gomes no imbricamento com as entidades religiosas, nas quais estas últimas possibilitaram a quebra de silenciamento dos povos indígenas de Crateús, o que acabou por mobilizar uma luta em prol de reinvindicações sociais; "As raízes indígenas de uma prática educativa" em que discorreu-se acerca do início da prática educativa de Maria Helena Gomes por meio de sua luta para a implantação da primeira escola indígena de Crateús; e "Considerações finais", seção em que se retoma a problemática e objetivo da pesquisa para respondê-los compilando os principais resultados e discussões, bem como inferindo limitações e sugestões. 


\section{Percurso teórico-metodológico}

O estudo insere-se no campo da história da educação, amparando-se teoricamente na história cultural. Importa salientar que a compreensão desta corrente historiográfica se insere nas concepções surgidas a partir do fim da década de 1920, com o início do movimento conhecido como escola dos Annales, que possibilitou à História abranger novos sujeitos, fontes, métodos e objetos de pesquisa (LE GOFF, 2014). Essa abordagem amplia o entendimento do que pode ser designado como fontes históricas, compreendendo-as como todo vestígio que traduz a história do homem no tempo, seja por meio de cartas, pinturas, fotografias, documentos pessoais, narrativas orais etc. (BURKE, 1992). Nessa seara, permite aprofundar-se na vida de sujeitos comuns, excluídos ou invisibilizados pela história oficial. Com isso, passa-se a valorizar o individual, as subjetividades e as singularidades de contextos específicos que não são passíveis de análise por lentes macro históricas (LORIGA, 2011).

Considerando que este estudo se propõe a desenvolver uma biografia, faz-se necessário compreender a conceituação utilizada acerca do gênero biográfico, assim como a importância acerca dos estudos sobre histórias de vida de educadoras (FIALHO; SANTOS; SALES, 2019). Segundo os autores Palhari e Machado (2014), a biografia é uma metodologia com potencialidade de diálogo entre o individual e o sociocultural, que fornece subsídios para se entender o indivíduo em várias dimensões. Tal modo torna-se factível para melhor compreender contextos a partir da vida individual, desde que esta não seja heroicizada ou utilizada com mote de exemplificação, já que a narrativa histórica e os aspectos constituintes da sociedade de outrora não comportam uma verdade única ou inquestionável (LEVI, 1992).

Importa destacar, com efeito, que o gênero biográfico deste estudo não pretende consagrar pessoas, nem se centra em figuras de heróis ou grandes mártires (RODRIGUES, 2015), mas lança novos olhares numa perspectiva microhistórica (LORIGA, 2011). Trata-se de uma compreensão de que o fazer histórico se desvela na ação cotidiana dos sujeitos e grupos sociais silenciados pela história oficial, apresentando uma nova dimensão na edificação de identidades e da memória social (NORA, 1993). Porém, enfatiza-se que uma biografia não se restringe somente às particularidades da vida de um indivíduo, mas busca a compreensão de um todo pela parte, ao desvelar aspectos de um contexto sócio-histórico específico que amplia a compreensão acerca da história da educação (FIALHO et al., 2020; XAVIER; FIALHO; VASCONCELOS, 2018). 
A biografia de Helena Potiguara foi desenvolvida com suporte metodológico na história oral. "Essa metodologia que trabalha fundamentalmente com narrativas, relatos ou entrevistas orais permite que o pesquisador elabore análises individuais e coletivas e desenvolva compreensões específicas, com maior riqueza de detalhes e minúcias" (CARVALHO; FIALHO, 2017, p. 102). Logo, permitiu não somente uma compreensão historiográfica elaborada por intermédio de narrativas de fatos e acontecimentos, mas uma perceptibilidade e observação crítica sobre arquétipos que permeiam a história da educação das mulheres indígenas no Brasil, em especial no Ceará, sob suas percepções.

Lançar luz sobre à educação feminina é estar ciente de que, segundo Barcellar (2006), as mulheres são um grupo social não estudado propositadamente para favorecer e garantir a hegemonia masculina de poder. E quando se trata de indígenas, o silenciamento e a invisibilidade se expressam duplamente: pela condição de mulher e pela etnia. Afinal, aos indígenas, historicamente, atribuiu-se uma compreensão equivocada de que eram seres pouco evoluídos, primitivos, rudes e preguiçosos, que colaboravam com o atraso socioeconômico, para justificar todo o massacre histórico. Como ressalta Marques (2017), não se levava em consideração suas percepções e a valorização de suas culturas, relegando esse grupo social à invisibilidade na história da educação.

A História Oral nessa pesquisa foi compreendida como a metodologia que mais adequou-se à pesquisa biográfica em relato, por envolver mulheres indígenas, pois, como leciona Jucá (2011, p. 52), oferece "uma possibilidade de diversificar as fontes a serem trabalhadas, passando a valorizar o significado da memória na compreensão da vida humana". Bueno e Cárdenas (2018, p. 30, tradução nossa) acrescentam:

A História Oral se define, então, como a construção e interpretação do passado a partir das memórias e das recordações expressas mediante o testemunho oral de quem participou diretamente ou foi contemporâneo ao fato estudando, acompanhando, confrontando e cotejando com outros documentos e fontes 5 .

Ante essa compreensão, a oralidade de Helena Potiguara foi o objeto dessa pesquisa, que possibilitou a constituição e a interpretação do passado. Suas memórias tornaram factível o “[...] estudo das diferentes formas de articulação de atores e grupos de interesse, o estudo de padrões de socialização e de trajetórias de indivíduos" (ALBERTI, 2006, p. 166). Elaborouse, todavia, uma narrativa biográfica relacionada à História da Educação brasileira, em caráter

${ }^{5}$ La Historia oral se define, entonces, como la construcción y la interpretación del pasado a partir de las memorias y los recuerdos expressados mediante el testimonio oral de quien participó directamente o fue contemporáneo al hecho estudiando, acompanãndo, confrontando y cotejando com outros documentos o fuentes (BUENO; CÁRDENAS, 2018, p. 30). 
local, que pressupõe "[...] a possibilidade de conhecer e reconhecer seus(suas) educadores(as), suas ações e práticas educativas nos diferentes contextos históricos" (XAVIER; FIALHO; VASCONCELOS, 2018, p. 156).

A educadora indígena foi selecionada através de outras leituras, como Palitot (2008; 2009), Thomé (1994) e Lima (2010), que a elencavam como a personagem inicial da educação indígena entre o povo Potiguara. $\mathrm{O}$ contato com a entrevistada se deu por intermédio de conversa nas redes sociais com seu filho, Renato Potiguara, que é o atual cacique e o qual fez a intermediação para a entrevista, com a marcação do dia e local mediante critério da educadora: 5 de março de 2020, no Instituto Federal do Ceará campus Fortaleza, ocasião em que teriam aula de uma especialização que estavam cursando.

A entrevista com Helena Potiguara teve duração média de uma hora, ela foi gravada, transcrita, textualizada, validada e utilizada como fonte primária, entrecruzada com outras fontes (como livros, artigos, teses e dissertações), com o intuito de desvelar os enredos pertinentes à história da educação do povo Potiguara. Interessa esclarecer que a entrevista foi realizada após ser aprovado o projeto de pesquisa "Educação e Educadoras no Ceará do Século XX: práticas leituras e representações", coordenado pela pesquisadora Lia Machado Fiuza Fialho, no Comitê de Ética em Pesquisa (CEP), sob parecer favorável de número 2.585.705/2018.

Mediante o consentimento de Helena Potiguara, efetivou-se o encontro previamente agendado, no qual ela foi entrevistada pessoalmente em particular, após a leitura do Termo de Consentimento Livre e Esclarecido (TCLE), que informava o objetivo da pesquisa, a ausência de benefícios, seus riscos, a não preservação da identidade, forma de participação, a possibilidade de desistência a qualquer momento etc. Posteriormente houve a validação da transcrição, que permitiu à Helena Potiguara a leitura do texto transcrito literalmente, para que ela pudesse fazer ajustes necessários visando à qualificação das informações que foram concedidas.

A análise das narrativas priorizou problematizar os paradoxos emergentes no percurso social e educativo da biografada, ao salientar as nuances e as singularidades que permearam sua trajetória formativa e política (CARVALHO; FIALHO, 2017). Para isto, houve "o desenvolvimento de problematizações sobre a educação de mulheres ou mesmo para as mulheres, propulsoras de possibilidades de romper paradigmas e questionar certos dogmas e estereótipos consagrados pelo senso comum ou pelas generalizações que subjugam o feminino" (FIALHO; DUKE, 2019, p. 4). Essa discussão resultou em uma narrativa biográfica sobre a formação educativa da professora indígena Helena Potiguara, que analisou 
suas interpretações acerca da educação indígena diferenciada e das mobilizações coletivas que resultaram na constituição de cinco grupos étnicos na cidade de Crateús (Tupinambá, Kariri, Kalabaça, Potiguara e Tabajara), como será apresentado na seção que segue.

\title{
Karatius: A quebra de silenciamento
}

Maria Helena Gomes, mulher indígena da etnia Potiguara, nasceu no dia 20 de março de 1954 no Piauí, mas foi registrada como cearense da cidade de Novo Oriente. É filha de Gonçala Ferreira do Nascimento e Manoel Gomes de Oliveira, sendo a primogênita de doze irmãos. Os pais se conheceram no Piauí, onde haviam ido morar ainda crianças, fugindo da seca que assolava o sertão cearense, no entanto, eles voltaram com a família para Crateús no ano de 1971. A autora Thomé (1994, p. 183) traz um relato de Helena Potiguara sobre este período:

\begin{abstract}
Vim de lá com meus pais com 8 anos de idade, em 1962. A gente ficou morando vizinho a Novo Oriente, na serra. Minha vida de criança era ajudar a criar os irmãos. Minha mãe ficava trabalhando na roça com meu pai, e eu ficava em casa cuidando das crianças. Não ia a escola porque no interior não tinha. Às vezes o professor dava um mês de aula, dois meses, mas era difícil acontecer.
\end{abstract}

Ao falar sobre sua escolarização, Helena Potiguara conta que foi alfabetizada somente aos 12 anos, numa escola particular, pequenina, do interior cearense, por causa da ausência de instituições educativas nas proximidades de sua residência e pela necessidade de colaborar com o trabalho doméstico. Ela acrescenta que se casou muito jovem, entre 15 e 16 anos, e do matrimônio nasceram 3 filhos. Mas o casamento acabou pela ausência do marido que trabalhava viajando e passava quatro meses do ano distante.

Em 1983, tendo que sustentar sozinha os filhos, e com a região dos Sertões de Crateús sendo assolada pela seca, ela alistou-se para trabalhar no "Bolsão da Seca" de Santa Fé, que consistia no cadastramento de mulheres por parte do batalhão da cidade para carregar água do açude do governo para a construção da parede do açude de Santa Fé. Era uma frente de emergência, criada para amenizar o sofrimento das vítimas da seca (PINHEIRO, 2012). Helena trabalhou 11 meses carregando latas d'água de 18 litros na cabeça, de 6 às 11 e de 13 às 17 horas. A autora Lima (2010, p. 159) traz uma fala de Helena Potiguara sobre este período:

[...] Eu vinha de um trabalho no bolsão da seca, no ano de 1983, foi cinco anos de seca, desde 1979 a 1983. Os bolsões eram comandados pelo 
exército, do IV Batalhão de Engenharias e Construções (BEC). A gente sofreu muito lá. Além da fome, da falta d'água, da necessidade, ainda tinha mais a presença do comandante, do Major Borge.

Foi durante os trabalhos no "Bolsão da Seca" que ela conheceu o padre Alfred Kunz, conhecido como padre Alfredinho, que a convidou para ir à Igreja de São Francisco. Por intermédio do sacerdote, Helena Potiguara tornou-se membro da Irmandade do Servo Sofredor (ISSO) e ingressou nas pastorais da igreja católica; como muitos outros indígenas que foram cooptados pela Igreja Católica (MAROLDI; LIMA; HAYASHI, 2018). A partir de então, ela encantou-se pelo trabalho com os sem-teto desenvolvido por Dom Fragoso ${ }^{6}$, tornando-se colaboradora nas ações da diocese de Crateús, quando deu início à sua mobilização política e social da luta pelas causas indígenas e sentiu necessidade de prosseguir nos estudos. No ano seguinte, em 1984, Helena Potiguara voltou à escola regular, como narra: "Vinte anos depois voltei a sala de aula no MOBRAL" [...] dava direito a me matricular numa escola do estado a nível de $5^{\text {a }}$ série. E assim eu fui matriculada. Conclui o ensino fundamental da $5^{\circ}$ ao $8^{\circ}$ ano no município de Crateús na escola Lions, começando em 1986".

A constituição da mobilização social e política pelo reconhecimento étnico dos grupos indígenas da cidade de Crateús, durante a década de 1990, foi empreendida por segmentos da sociedade, entre eles a coletividade dos sujeitos indígenas e as ações pastorais da igreja católica. A diocese de Crateús, liderada pelo Bispo Dom Antônio Fragoso, realizava um trabalho com grupos sem-teto, que envolvia o movimento indígena na cidade de Crateús e dos demais municípios da região circunvizinha. Busca-se valorizar as "suas origens nestas experiências da organização da igreja voltadas para a libertação dos grupos sociais mais pobres" (PALITOT, 2009, p. 271).

É importante mencionar que a diocese já realizava outro trabalho semelhante, intitulado Pastoral do Negro, que realizava conscientizações sobre negritude, do qual Helena Potiguara também fez parte. A Pastoral do Negro, além de elaborar os trabalhos de conscientização, mobilizava famílias que não possuíam moradia, organizando-as para realizar ocupações em terras públicas. Helena Potiguara, inclusive, participou de muitas dessas ocupações. Palitot (2008, p. 9), publicizou narrativas em que ela explica:

\footnotetext{
${ }^{6}$ Dom Antônio Batista Fragoso nasceu na Paraíba em 1920, e ordenou-se sacerdote em 1944. No dia 28 de abril de 1964 foi nomeado primeiro bispo de Crateús pelo Papa Paulo VI; função que exerceu até fevereiro de 1998, quando apresentou renúncia por limite de idade (Conferência Nacional dos Bispos do Brasil, 2019).

${ }^{7}$ O Movimento Brasileiro de Alfabetização (MOBRAL) foi órgão instituído durante a ditadura militar, pelo governo federal no governo de Emílio Garrastazu Médici, por meio do Decreto $\mathrm{n}^{\circ} 62.455$, de 22 de março de 1968, com o objetivo inicial de alfabetizar pessoas acima da idade escolar convencional (15 a 35 anos), e depois incluindo a faixa etária de 9 a 14 anos.
} 
Tudo iniciou por volta de 1988 quando o tema da Campanha da Fraternidade era sobre negro, que nós iniciamos um trabalho nesta região, nesta região onde moro que é a Fátima II, visitando todas as famílias negras. E nestas visitas nós conseguimos nos organizar e conversar sobre os principais problemas que o nosso povo enfrentava. Então descobrimos que era importante não só contar a história de um povo negro mas também encontrar um lugar para morar; porque ninguém tinha um lugar para morar.

Helena Potiguara esteve envolvida em quase todas as ocupações, sendo: a primeira, a da Terra Prometida, em 11 de agosto de 1990; a segunda, a Nova Terra, em 30 de agosto de 1991; a terceira, a de Vila Vitória, em 17 de agosto de 1993; a quarta, a da Terra Livre, em 05 de agosto de 1995; a quinta, a de Campo Verde, em 1996. A atuação dela no movimento negro lhe permitiu visualizar a importância de uma organização indígena. Afinal, foram nessas diversas mobilizações e ocupações que foi constituída a oportunidade de identificar famílias com etnicidade indígena, pois esses momentos favoreciam o contato com pessoas que passaram a compor a pastoral e demais moradores que assumiam a identidade indígena.

Concomitante ao trabalho com a pastoral e com as ocupações, Helena Potiguara volta a estudar, em 1990, no Colégio Regina Pacis, para concluir o ensino médio normal. Finalizou o curso em quatro anos, dos quais foram três anos das disciplinas regulares e mais um ano de especialização para o magistério de segundo grau. Durante esse período, colaborou com o projeto de Dom Antônio Fragoso, especialmente porque o bispo confiou à missionária belga Margareth Malfliet um novo desafio: o trabalho de mapeamento com as famílias que eles acreditavam serem pessoas descendentes de indígenas. Assim, “[...] a ação pastoral visou resgatar as 'raízes indígenas' dos moradores de Crateús. Com o andamento do processo, a pastoral passou a reivindicar o reconhecimento da identidade indígena e o acesso aos direitos assegurados na Constituição Federal às populações indígenas” (LIMA, 2010, p. 132).

Pinheiro (2012) descreve a atuação religiosa nos processos de identificação indígena no Ceará, e em um trecho de suas pesquisas ela relata o momento anteriormente mencionado por Helena Potiguara sobre o início da sua formação educativa realizada mediante o programa Mobral e o início do trabalho da Pastoral Raízes Indígenas.

Ao integrar um programa de alfabetização de adultos, na condição de aluna, Helena Potyguara participou de um evento escolar em razão das comemorações dos 500 anos do chamado 'descobrimento do Brasil'. Durante o evento, aconteceu o encontro da liderança com Dom Fragoso, no momento em que este se pronunciou acerca do desejo de apoiar iniciativas voltadas para a valorização da memória e da cultura indígena no sertão cearense. Em seu discurso, Fragoso reconheceu que a diocese de Crateús estava defasada no que se referia à sua missão de construir uma 'igreja popular libertadora' e por isso decidiu pedir à freira Malfliet que se 
responsabilizasse pela criação de uma pastoral dedicada às questões indígenas (PINHEIRO, 2012, p. 125).

A primeira reunião foi realizada no quintal da casa de Helena Potiguara, no ano de 1992, da qual participaram a missionária Margareth, Mazé Kalabaça e Tereza Kariri, com o apoio de Maria Amélia Leite ${ }^{8}$. Estas mulheres foram protagonistas no levantamento da etnicidade dos indígenas de Crateús (GOMES; VIEIRA; MUNIZ, 2007). Após a reunião, decidiram colocar o nome do projeto de "Pastoral Raízes Indígenas". A partir disto iniciava-se a quebra de silenciamento, o reconhecimento e a reconstituição da história desse grupo étnico. Inclusive, Helena Potiguara cedeu uma entrevista para a Revista Mensageiro, do Conselho Indigenista Missionário (CIMI), na qual ela versava sobre o início dos trabalhos com a Pastoral Raízes Indígenas:

Ai a gente veio descobrir que lá não estava só a força do negro, tinham também outras forças e suas influências: através de nossas pesquisas das nossas histórias que os mais velhos contavam, descobrimos que a maioria éramos índios, aliás somos índios porque do nosso passado, dos nossos avós, dos nossos tetravós nasce esta realidade de hoje (REVISTA MENSAGEIRO, 2000 apud PALITOT, 2008, p. 10).

Foi nesse processo de rememoração do passado junto aos integrantes que Helena Potiguara e a irmã Margareth Mafliet confeccionaram um mapa imaginário de Crateús e da região do entorno da cidade, fazendo marcações com lugares que remetiam à memória indígena e angariando adeptos para atuar nessa iniciativa.

Com o andar do processo cresceram as adesões, e a configuração de pastoral tornou-se limitada diante dos anseios de seus membros. As novas adesões e a notícia do afastamento de Dom Fragoso da Diocese de Crateús os impulsionou a buscar outra forma de organização. Diante da incerteza quanto ao apoio do futuro bispo, passaram a buscar autonomia em relação à Igreja. Surgiu então o Conselho Indígena de Crateús e Região (CINCRAR) no ano de 1992, que teve sua importância reafirmada com a necessidade de uma instituição com personalidade jurídica para gerir os recursos da educação escolar indígena (LIMA, 2010, p. 180).

O Conselho Indígena de Crateús e Região (CINCRAR) foi extinto no ano de 2007, após 12 anos de funcionamento. Palitot (2008, p. 273), explica que isso

\footnotetext{
${ }^{8}$ Maria Amélia Leite é uma missionária do Conselho Indigenista Missionário (CIMI), reconhecida no estado do Ceará por sua atuação junto há vários povos indígenas e idealizadora da Associação Missão Tremembé - AMIT. O CIMI é um organismo vinculado à Conferência Nacional dos Bispos do Brasil (CNBB), criado em 1972. A atuação missionária do conselho conferiu um novo sentido ao trabalho da igreja católica junto aos povos indígenas.
} 
[...] ocorreu após discordâncias acerca da gerência de recursos federais por parte da última diretoria do conselho, o que resultou na sua desativação e no surgimento de cinco novas associações indígenas: Associação Indígena dos Kariri de Cratéus (AI-KA-CRA), que inclui também Tabajara, Potyguara e Tupimambá; Associação Raízes Indígenas dos Potyguara em Crateús (ARINPOC); Associação dos Povos Indígenas Tabajaras em Crateús (APITC), dos Tabajara da Nova Terra, migrados do Pé de-Serra do Ipu; a Associação da Aldeia Vila Vitória - Favela (AVFVLA), dos Tabajara da Vila Vitória, e a Associação Indígena Calabaça de Crateús (AICC), que congrega os Calabaça, dispersos pela cidade.

Tais associações, como pode-se observar, reuniam famílias indígenas de grupos étnicos distintos.

\title{
As raízes indígenas de uma prática educativa
}

Nesse interím Helena Potiguara ingressa no nível superior, pois passa a "estudar a Pedagogia a nível de $3^{\circ}$ grau que é a faculdade na Universidade do Vale do Acaraú (UVA) de Sobral, numa extensão no município" (GOMES, 2020). Quando finalizou o curso partiu para a pós-graduação, para cursar a especialização em Formação de Professores na Universidade Estadual do Ceará (UECE), também em Crateús.

\begin{abstract}
E sempre carregava comigo o sonho de ter uma escola. Do jeito que a gente pensa e idealiza a construção do saber no meio do povo mais simples e, principalmente, nos povos indigenas, que é as minhas raízes enquanto etnia. Sou descendente de povo indio e tem uma misturinha de negro no meio também (GOMES, 2020).
\end{abstract}

O movimento da pastoral também possibilitou a parceria com outras organizações que atuavam junto às populações indígenas do Ceará. No início da organização da educação indígena diferenciada liderada por Helena Potiguara, uma parceria entre a Pastoral Raízes Indígenas e a Associação Missão Tremembé (AMIT) possibilitou, no ano de 1993, à Helena Potiguara uma experiência de intercâmbio de 12 dias com o povo Tremembé, que estava em processo de implantação das primeiras escolas indígenas do estado do Ceará. Ela também teve a oportunidade de conhecer a escola do povo indígena Tapeba.

Acerca do intento da criação da escola indígena em Crateús, Helena Potiguara infere:

Bem, no princípio ninguém queria que eu criasse essa escola. Eu digo as outras instituições. Mas o sonho era muito grande na cabeça e o sentimento no coração, o desejo também. Ai eu ia para o CREDE, insistia, insistia e eles não queriam nem saber. Quando eu vi que eles não iam deixar. Aí eu falei: ah, pois então, eu vou começar por minha conta. Isso foi no dia 4 de abril de 1994, que eu fui a última vez lá insistir e não deu certo, aí fui criar por minha conta. Ai nós tínhamos feito um acampamento terra livre com pessoas que não tinham condições de pagar aluguel e fizemos uma turma só com adultos. E criamos a Escola Raízes Indigenas. A professora era eu, e 
ensinava os adultos. Tinham muitos adultos, que eram das famílias que não tinham onde morar e ficavam participando das aulas a noite (GOMES, 2020).

Assim nascia a primeira organização educacional entre os indígenas de Crateús, visto que estes até então frequentavam as escolas formais dos não-indígenas. Sobre este episódio inicial a autora Lima (2010, p. 198) explicita que:

Os dois primeiros professores (Helena e Hector), como foi citado, eram indígenas que atuavam em um programa de alfabetização para adultos criado pela Diocese de Crateús. As salas de aula funcionavam nas sedes comunitárias da Vila Vitória e Terra Livre. Em 1996 duas novas salas foram abertas no Maratoan e no Altamira. Nesta fase foi comum duas pessoas assumirem a sala de aula e dividirem o salário. Em 1998, solicitaram a abertura de turmas em Monsenhor Tabosa e Poranga.

As atividades da Escola Raízes Indígenas foram se expandindo na região caracterizada pela informalidade e ausência total de recursos, assim Helena Potiguara nos conta que: "Não tinha merenda, não tinha material, não tinha nada, só mesmo a força de vontade e povo que acreditava" (GOMES, 2020). As salas de aula funcionavam em sedes comunitárias e na casa dos professores indígenas e, ratificando a narrativa da educadora indígena Helena Potiguara, não havia material didático, merenda escolar para as crianças, sequer pagamento de salário aos professores, sendo esses geralmente voluntários. Quando finalmente foram conquistados os recursos públicos para pagar os salários dos professores, esses levaram oito meses para serem concedidos.

Importa destacar uma ajuda importante, de uma bancária, que cedia papeis usados apenas de um lado: “[...] uma moça que trabalhava no Banco do Brasil, Socorrinha Sales, me disse: Helena, eu vou juntar papel, papel usado para sua escolinha. Aí toda sexta-feira eu ia lá pegar maços de papel usado do banco. Aí nós aproveitava" (GOMES, 2020).

Helena Potiguara revela entusiasmo ao rememorar sobre o início de uma organização escolar indígena diferenciada:

E foi tão... foi um sucesso né?! Todo mundo queria, os que estavam dentro da escola. Ai mais tarde, anos depois, a gente estendeu para outros bairros; bairro da Maratoan, bairro da Altamira, Planaltina, Nova Terra, Terra Livre, Vila Vitória. Tudo eram acampamentos que a gente tinha animado o povo a fazer. Ai a gente instalou um bocado. Levei pro Novo Oriente. Hoje a escola lá se chama Antônio Gomes. Foi muito bonito também. Ai então, nós conseguimos e os pais gostavam tanto da escola que achavam importante colocar as crianças pequenas. Aí foi ai que nós começamos também com crianças pequenas. No espaço que os pais estudavam de noite, os pais colocavam os filhos durante o dia (GOMES, 2020). 
A educação inicialmente para indígenas adultos logo ampliou-se para o público infantil. Ante a demanda considerável, no ano de 1999 Helena Potiguara foi à casa de Dom Jacinto, que com a saída de Dom Fragoso era o atual bispo da diocese de Crateús, para escreverem um projeto acerca do pagamento de professores indígenas, assim como a autora Lima (2010, p. 181) transcreve a fala de Helena Potiguara:

Levamos (o projeto) pra apresentar em Caucaia com todos os índios. Nós sabíamos que o Naspolini (Antenor Naspolini, Secretário de Educação do Estado) ia estar lá. Aí nós levamos. Eu apresentei. A Teka disse: - Helena tu apresenta e eu defendo se houver necessidade. Depois que apresentamos, o Naspolini disse que era impossível regularizar pagamento para professor indígena e construir escola. "Isso é impossível de se realizar. Eu nasci e me criei sonhando em pegar o sol assim que ele nascesse e isso nunca aconteceu. Até hoje ainda não peguei”. Ele soltou essa piadinha, mas nós seguimos em diante e defendemos o nosso peixe, dissemos que era possível. Até que no fim ele disse: Eu posso levar esse projeto e apresento lá em Brasília, mas sem nenhum compromisso. Foi aí que a Mazé (funcionária da SEDUC) disse que já que ele estava disposto a levar o projeto pra Brasília, ela sugeriu que a gente ampliasse, colocasse a nível de estado e não mais a nível de região de Crateús. Nós ampliamos e foi uma vitória. Foi esse projeto que deu a oportunidade. Aí foi preciso criar as associações rápido. Nós já tínhamos o CINCRAR. Através da associação era para vir o pagamento dos professores. Nós fizemos um acordo entre nós que todos os professores, independente da formação, por turno, ia ganhar duzentos reais. Assinamos por dois anos. Foi bom por que o CINCRAR já estava no ponto.

A aprovação do projeto foi conseguida, mas era necessário superar toda a burocracia exigida. Helena Potiguara explica que para construir a escola, foi argumentado que os indígenas já tinham que ter o pedaço de terra no qual seria construída a escola, no entanto, seu povo não possuía, pois moravam na periferia da zona urbana da cidade de Crateús. "Então, fizemos a retomada num pedaço de terra pública e era uns 100 metros quadrado e fizemos uma escola muito bonita e boa. O governo do estado do Ceará tomou de conta, através da Secretaria de Educação (SEDUC)" (GOMES, 2020).

As reinvindicações sobre equipamentos, construção do prédio da escola, pagamento de salário e formação de professores, manutenção de alunos, foram lideradas pela indígena Helena Potiguara: "Nós tivemos a nossa escola depois de muita luta. O prédio da escola só foi construído pelo governo do estado em 2008. E o governo do estado inaugurou em 2009" (GOMES, 2020). Atualmente, no ano de 2020, Helena Potiguara está cursando o curso de Licenciatura Intercultural Indígena pela Universidade Federal do Ceará (UFC), e é diretora da Escola Raízes Indígenas de Crateús, no bairro do Campo Velho, que conta com mais de 400 alunos matriculados, sendo $90 \%$ deles de origem indígena. 


\section{Considerações finais}

O estudo questionou como uma mulher indígena residente no município de CrateúsCE conseguiu escolarização para tornar-se professora indígena e galgar posição de liderança comunitária reconhecida por suas práticas educativas e políticas diferenciadas. Essa inquietação foi respondida a partir de uma pesquisa científica do tipo biográfica, com o escopo de compreender a formação educativa e as práticas políticas, tecidas pela educadora Helena Potiguara, que lhe conferiram destaque na comunidade Potiguara (1954-2009).

A história de vida de Helena Potiguara permitiu observar que ela rompeu paradigmas ao reivindicar sua identidade étnica, ganhando notoriedade e colaborando para a luta coletiva de sua região, em especial no âmbito educacional, pois desencadeou um processo de conscientização da comunidade que culminou no fomento a um processo escolar diferenciado para os povos indígenas da região de Crateús. Afinal, foi por meio das atividades realizadas - mobilizações, levantamento do histórico das famílias e as tomadas de terras públicas - que houve a quebra de silenciamento da identidade étnica e a organização do movimento indígena local, que culminou na estruturação das escolas e no modelo de educação indígena diferenciada.

O que podemos inferir é que a prática política e educativa de Helena Potiguara ensejou um protagonismo em Crateús, visto que mesmo a educadora tendo tecido seu percurso pedagógico em espaços escolares formais não indígenas, ela vislumbrou uma educação indígena diferenciada voltada para a realidade social e cultural de seu povo, o que lhe conferiu destaque. Entende-se também que Helena não enveredou seu percurso educativo em escolas indígenas, pois estas não existiam no estado do Ceará, afinal, conforme Pereira (2020), a primeira escola dessa natureza foi implementada apenas em 1991, pela educadora indígena Raimunda Marques do Nascimento, da etnia Tremembé, em Itarema. No entanto, defendia uma educação diferenciada do modelo tradicional adotado nas escolas regulares das proximidades, que não consideravam a história e memória de seu povo.

Percebe-se que foi inicialmente por meio do movimento iniciado pela pastoral, depois liderado pela indígena Helena Potiguara, que se iniciou uma mobilização social que resultou na construção de mais 8 escolas indígenas na região de Crateús e seu entorno, gerenciadas pela Coordenadoria Regional de Desenvolvimento da Educação (CREDE 13). As escolas estão distribuídas entre as etnias Potiguara, Kalabaça, Kariri, Tabajara e Tupinambá. No rol do conteúdo didático, as escolas contam com aulas que buscam resgatar as descendências 
indígenas por intermédio das culturas dos ancestrais, tendo como especificidade se fortalecer enquanto grupos étnicos que possuem particularidades socioculturais e históricas que necessitam ser preservadas e valorizadas.

\section{REFERÊNCIAS}

ALBERTI, V. Fontes orais: histórias dentro da história. In: PINSKY, C. B. (Org.). Fontes históricas. São Paulo, SP: Contexto, 2006. p. 155-202.

BARCELLAR, C. Fontes documentais. In: PINSKY, C. B. (Org.). Fontes históricas. 2. ed. São Paulo, SP: Contexto, 2006.

BRASIL. Constituição (1988). Constituição da República Federativa do Brasil. Brasília, DF: Senado, 1988.

BRASIL. Decreto n. 26, de 4 de fevereiro de 1991. Dispõe sobre a Educação Indígena no Brasil. Brasília, DF, 05 fev. 1991. Disponível em:

http://www.planalto.gov.br/ccivil_03/decreto/1990-1994/D0026.htm. Acesso em: 19 nov. 2020.

BRASIL. Lei número 9394, 20 de dezembro de 1996. Lei de Diretrizes e Bases da Educação Nacional. Brasília, DF, 23 dez. 1996.Disponível em:

http://www.planalto.gov.br/ccivil_03/leis/19394.htm. Acesso em: 19 nov. 2020.

BUENO, F. C.; CÁRDENAS, A. U. A. História y memórias un aporte al estado de la discusion. Bogotá, Colômbia: Universidad del Rosario. Distrital Francisco Jose de Caldas, Universidad Pedagógica Nacional de Colombia, 2018.

BURKE, P. (Org.) A escrita da história: novas perspectivas. São Paulo, SP: Unesp, 1992.

CARVALHO, S. O. C.; FIALHO, L. M. F. A metodologia da história oral em pesquisas educacionais. In: FIALHO, L. M. F.; LOPES, T. M. R. (Orgs.). Docência e formação: percurso e narrativas. Fortaleza, CE: Eduece, 2017.

CEARÁ. Decreto n. 25.970, de 31 de julho de 2000. Cria as escolas indígenas que indica e dá outras providências. Diário Oficial do Estado: série 2, ano 3, Fortaleza, CE, n. 147, 02 ago. 2000 .

DOSSE, F. O desafio biográfico: escrever uma vida. São Paulo, SP: Editora da Universidade de São Paulo (USP), 2015.

FIALHO, L. M. F. et al. O uso da história oral na narrativa da história da educação no Ceará. Práticas Educativas, Memórias e Oralidades - Rev. Pemo, Fortaleza (CE), v. 2, n. 1, p. 113, 2020. Disponível em: https://revistas.uece.br/index.php/revpemo/article/view/3505. Acesso em: 25 nov. 2020.

FIALHO, L. M. F.; DUKE, D. Apresentação. Revista Educação Unisinos, São Leopoldo (RS), v. 23, n. 1, jan./mar. 2019. Disponível em: 
http://revistas.unisinos.br/index.php/educacao/article/view/18199/60746739. Acesso em: 19 ago. 2019.

FIALHO, L. M. F.; SANTOS, F. M. B.; SALES, J. A. M. Pesquisas Biográficas na História da Educação. Cadernos de Pesquisa, São Luís (MA), v. 26, p. 11-29, 2019. Disponível em: http://www.periodicoseletronicos.ufma.br/index.php/cadernosdepesquisa/article/view/ 12743/6898. Acesso em: 22 out. 2019.

GOMES, A.; VIEIRA, J. P.; MUNIZ, J. Povos Indígenas no Ceará: organização, memória e luta. Memorial da Cultura Cearense, do Centro Dragão do Mar de Arte e Cultura, 2007.

GOMES, M. H. Entrevista concedida a Arliene Stephanie Menezes Pereira. Ceará, 5 mar. 2020 .

JUCÁ, G. N. M. A oralidade dos velhos na polifonia urbana. Fortaleza, CE: Premius, 2011.

LE GOFF, J. História e memória. Campinas, SP: Unicamp, 2014.

LEVI, G. Sobre a micro-história. In: BURKE, P. (Org.). A escrita da história: novas perspectivas. São Paulo, SP: Unesp, 1992.

LIMA, C. L. S. Etnicidade indígena no contexto urbano: uma etnografia sobre os Kalabaça, Kariri, Potiguara, Tabajara e Tupinambá de Crateús. 2010. 271 f. Tese (Doutorado em Antropologia) - Universidade Federal de Pernambuco, Recife, PE, 2010.

LORIGA, S. O pequeno x: da biografia à História. Belo Horizonte, MG: Autêntica, 2011.

MAROLDI, A. M.; LIMA, L. F. M.; HAYASHI, M. C. P. I. A produção científica sobre educação indígena no Brasil: uma revisão narrativa. Revista Ibero-Americana de Estudos em Educação, Araraquara, v. 13, n. 4, p. 931-952, 2018. Disponível em:

https://periodicos.fclar.unesp.br/iberoamericana/article/view/10211. Acesso em: 25 de nov. de 2020.

MARQUES, J. Além da história, a tradição oral: considerações sobre o ensino de história da África na educação básica. Educação \& Formação, Fortaleza (CE), v. 2, n. 2, p. 164-182, 2017. Disponível em: https://revistas.uece.br/index.php/redufor/article/view/142. Acesso em: 25 out. 2020.

NORA, P. Entre memória e história: a problemática dos lugares. Projeto História. Trad. Yara Aun Khoury. São Paulo, SP: Educ, 1993. n. 10, p. 7-28.

PALHARI, H. M. L.; MACHADO, C. J. S. Fios da Memória. In: FIALHO, L. M. F. et al. Pelos fios da memória. Fortaleza, CE: UFC, 2014.

PALITOT, E. M. Descobrir-se índio na cidade: as aldeias urbanas em Crateús/CE. In: REUNIÃO BRASILEIRA DE ANTROPOLOGIA, 26., 2008, Porto Seguro. Anais [...]. Porto Seguro, BA, 2008. 
PALITOT, E. M. Um quadro de multiplicidade étnica: os povos indígenas em Crateús. In: PALITOT, E. M. (Org.). Na mata do Sabiá: contribuições sobre a presença indígena no Ceará. Fortaleza, CE: Secult/Museu do Ceará/IMOPEC, 2009.

PEREIRA, A. S. M. P. Aninhá Vaguretê: corpo e simbologia no ritual do Torém dos índios Tremembé. 1. ed. Curitiba, PR: Appris, 2020.

PINHEIRO, J. D. Religiosos engajados e processos de identificação indígena no Ceará. Tellus, Campo Grande (MS), ano 12, n. 22, p. 107-132, jan./jun. 2012.

RODRIGUES, R. M. Biografia e Gênero. In: FIALHO, L. M. F.; VASCONCELOS, J. G.; SANTANA, J. R. (Org.). Biografia de mulheres. Fortaleza, CE: EdUECE, 2015.

THOMÉ, Y. B. T. Crateús. Um povo, uma igreja. São Paulo, SP: Edições Loyola, 1994.

XAVIER, A. R.; FIALHO, L. M. F.; VASCONCELOS, J. G. (Org.). História, memória e educação: aspectos conceituais e teórico-metodológicos. Fortaleza, CE: EdUECE, 2018.

\section{Como referenciar este artigo}

PEREIRA, A. S. M.; SOUSA, A. C. B.; FIALHO, L. M. F. Helena Potiguara: biografia da educadora indígena (1954-2009). Revista Ibero-Americana de Estudos em Educação, Araraquara, v. 16, n. esp. 3, p. 1386-1403, jun. 2021. e-ISSN: 1982-5587. DOI: https://doi.org/10.21723/riaee.v16iesp.3.15288

Submissão em: 05/02/2021

Revisões requeridas em: 30/03/2021

Aprovado em: 12/05/2021

Publicado em: 01/06/2021 